\title{
THE ANATOMICAL STUDY OF MITRAL VALVE ANNULUS IN THE HUMAN CADAVERIC HEARTS FOR BIOPROSTHESIS
}

Geethanjali. B.S ${ }^{* 1}$, Jayanthi V ${ }^{2}$, Kavimani ${ }^{3}$, Varsha Mokhasi ${ }^{4}$, Rajini. T ${ }^{5}$, Mohan kumar. $\mathrm{H}^{6}$.

${ }^{*}$ Associate professor, Department of Anatomy, East point college of medical science \& research centre, Bangalore, Karnataka, India.

${ }^{2}$ Professor \& Dean, Department of anatomy, Sapthagiri medical college \& research centre, Bangalore, Karnataka, India.

${ }^{3}$ Professor, Department of Anatomy, Balagi medical college, Tamil Nadu, India.

${ }^{4}$ Professor \& HOD, Department of Anatomy, Vydehi medical college \& research centre, Bangalore Karnataka, India.

${ }^{5}$ Professor, Department of Anatomy, Vydehi medical college \& research centre, Bangalore Karnataka, India.

${ }^{6}$ Professor, Department of ophthalmology, Sri Devaraj Urs medical college, Kolar, Karnataka, India.

\section{ABSTRACT}

Introduction: The unimpeded forward flow of blood across the mitral orifice depends upon a coordinated interaction between the mitral annulus, leaflets, chordae tendinae \& papillary muscle. Knowledge about the normal anatomy of mitral valve annular morphometry is important for assessing the valve pathologies and also in valve replacement surgery for a deceased valve

Materials and methods: 50 heart of embalmed adult human cadaver of both sex aged between 20-70 years were taken from the department of anatomy, VIMS \& RC. Parameters measured were annular diameter, circumference, area of mitral valve by using vernier caliper, measuring scale, cotton thread \& magnifying lens.

Results: In the present study mean value of mitral valve were, circumference of mitral valve was $8.19 \pm 1.01 \mathrm{~cm}$ in males, $7.76 \pm 0.99 \mathrm{cms}$ in females, diameter was $3.10 \pm 0.40 \mathrm{~cm}$ in males $\& 3.26 \pm 0.48 \mathrm{~cm}$ in females, area of mitral valve was $5.45 \pm 1.34 \mathrm{~cm}^{2}$ in males \& $4.89 \pm 1.20 \mathrm{~cm}^{2}$ in females. All the parameters of mitral valve annulus like circumference, diameter $\&$ area of valve was more in males except in females the diameter was more. There was no significant difference between male \& female values of mitral valve annulus.

Conclusion: Knowledge of normal measurements of the component parts of the mitral valve is essential for the surgeon during operation to assess the exact mechanical reason for valve insufficiency \& in development \& manufacture of prostheses for valvuloplasty.

KEY WORDS: Mitral Valve, Annulus, Bioprosthesis, Valve Replacement.

Address for Correspondence: Dr.Geethanjali. B.S, Associate Professor, Department of Anatomy, East point college of medical science \& research centre, Bangalore-560071, Karnataka, India. Phone number: 9739444178 E-Mail: geethamohan76@gmail.com

Access this Article online

Quick Response code

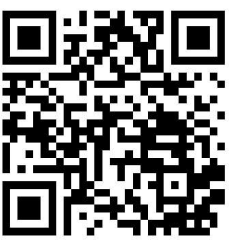

DOI: $10.16965 /$ ijar.2019.173
Journal Information

International Journal of Anatomy and Research

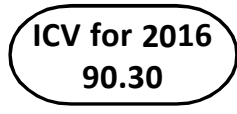

ISSN (E) 2321-4287 | ISSN (P) 2321-8967

https://www.ijmhr.org/ijar.htm

DOI-Prefix: https://dx.doi.org/10.16965/ijar

\section{Article Information}

Received: 14 Mar 2019

Peer Review: 14 Mar 2019

Revised: None
Accepted: 16 Apr 2019

Published (O): 05 May 2019

Published (P): 05 May 2019 


\section{INTRODUCTION}

The atrioventricular valvular complex of left ventricles, consists of the orifice and its associated anulus, the cusps, the supporting chordae tendineae of various types and the papillary muscles. The mitral orifice is a well-defined transitional zone between the atrial wall and the bases of the cusps. The anulus of the valve is made up of fibrocollagenous elements of varying consistency from which the fibrous core of the cusps take origin. These variations allow major changes in the shape and dimensions of the anulus at different stages of the cardiac cycle and ensure optimal efficiency in valvular action [1]. Louis A. Du Plessis et al [2] described that mitral valve inlet was larger than its outlet because of the oblique setting of the plane of the outlet orifice compensates for the discrepancy in size. The mitral annulus was in close proximity to the bundle of His, the coronary sinus, the aortic cusps, and other coronary vessels. Careless suturing during total valve replacement may damage these structures. Shamim et al [3] states that the dimensions of mitral valve do not show any racial difference, in a study by Krishnaiah et al [4] demonstrate that there was a marginal difference between Indian and western subjects and minimal difference between male and female with diameter and circumference of the mitral valve. These differences would be of paramount importance to a surgeon and will be crucial when valve replacements are being considered. Tie $C$ et al [5] reported in a study of control group of the right atrioventricular valve and in a comparative evaluation, that there were similar values for nonfixed and fixed hearts, as well as for those evaluated by echocardiograms.

The diseased mitral valve like stenosis \& prolapsed of valve is replaced by a prosthetic valve. Hence detailed knowledge about the normal anatomy of annulus of mitral valve is required for manufacturing prosthetic valves of appropriate dimensions and in surgical correction of damaged heart valves.

\section{MATERIALS AND METHODS}

50 hearts were taken from previously embalmed adult human cadaveric of both sex(21 male \&
29 female cadaveric hearts) of aged between 20-70 years were taken for the study from the department of Anatomy, Vydehi Institute of Medical Sciences and Research Centre, Bangalore. Cadavers with the history of any cardiac pathology were excluded from the study. Hearts which were hypertrophied, very small hearts, stenotic mitral valves were excluded from the study.

Dissection of specimens: Position and orientation of the heart and its chambers were confirmed. Left atrium was then opened by an incision through the right and left inferior pulmonary veins and the upper part of left atrial auricle was dissected. The heart thus opened was emptied of blood clots inside, washed thoroughly in running tap water. The mitral valve was inspected from above. An incision was made on the left margin of the heart and extended up to the apex of the heart. The left ventricle was opened and blood clots were removed from the left atrium. Thorough saline wash was given and bicuspid (Mitral valve) was observed and measured. The heart thus opened was emptied of blood clots inside, washed thoroughly in running tap water. In each heart a detailed examination of the mitral valve annulus was made [6].

The following parameters were measured and studied of Mitral valve

1. Annular Circumference was measured by using cotton thread at the attachment of leaflet.

2. Annular diameter was measured by calliper.

3. Area of the valve: was calculated using the formula C 2 / $4 \Pi$ Sq.cm (C- circumference of valve) [7].

Statistical Methods: Descriptive statistical analysis has been carried out in the present study. Results on continuous measurements are presented on Mean \pm SD (Min-Max) and results on categorical measurements are presented in Number (\%). Significance is assessed at $5 \%$ level of significance. Statistical software: The Statistical software namely SAS 9.2, SPSS 15.0, Stata 10.1, MedCalc 9.0.1, Systat 12.0 and R environment ver.2.11.1 were used for the analysis of the data, Microsoft word and Excel have been used to generate graphs, tables etc. 
Fig. 1: Shows measuring the annular circumference of mitral valve.
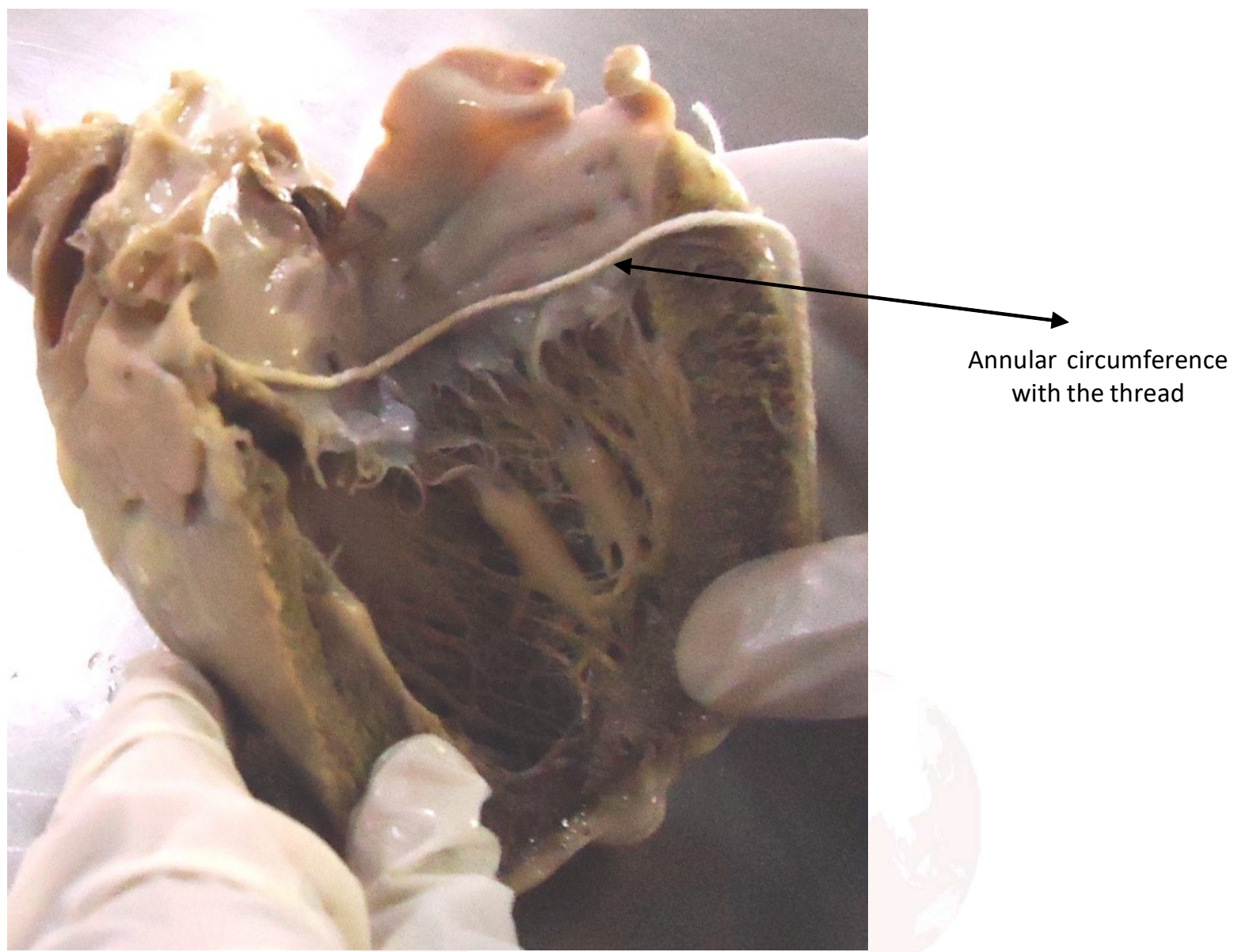

with the thread

\section{RESULTS}

In each heart a detailed examination of mitral valve was made and the following parameters were measured and the results were tabulated as follows:

Table 1: Represents the parameters of Mitral valve annulus.

\begin{tabular}{|c|c|c|c|c|c|c|}
\hline Variables & \multicolumn{2}{|c|}{ Minimum-maximum $(\mathrm{cms})$} & \multicolumn{2}{c|}{ Mean+SD $(\mathrm{cms})$} & $\mathrm{t}$-value & $\mathrm{P}$ - value \\
\hline & Male & Female & Male & Female & & \\
\hline Circumference & $6.7-10.4 \mathrm{~cm}$ & $6.2-9 \mathrm{~cm}$ & $8.19 \pm 1.01 \mathrm{~cm}$ & $7.76 \pm 0.99 \mathrm{~cm}$ & 1.506 & 0.139 \\
\hline Diameter & $2.15-4.1 \mathrm{~cm}$ & $2.46-4.42 \mathrm{~cm}$ & $3.10 \pm 0.40 \mathrm{~cm}$ & $3.26 \pm 0.48 \mathrm{~cm}$ & 1.448 & 0.154 \\
\hline Mitral valve area & $3.59-8.65 \mathrm{~cm}^{2}$ & $3.07-6.48 \mathrm{~cm}^{2}$ & $5.45 \pm 1.34 \mathrm{~cm}^{2}$ & $4.89 \pm 1.20 \mathrm{~cm}^{2}$ & 1.497 & 0.141 \\
\hline
\end{tabular}

Graph 1: Showing comparison of mitral valve annular circumference, diameter \& area between male \& female.

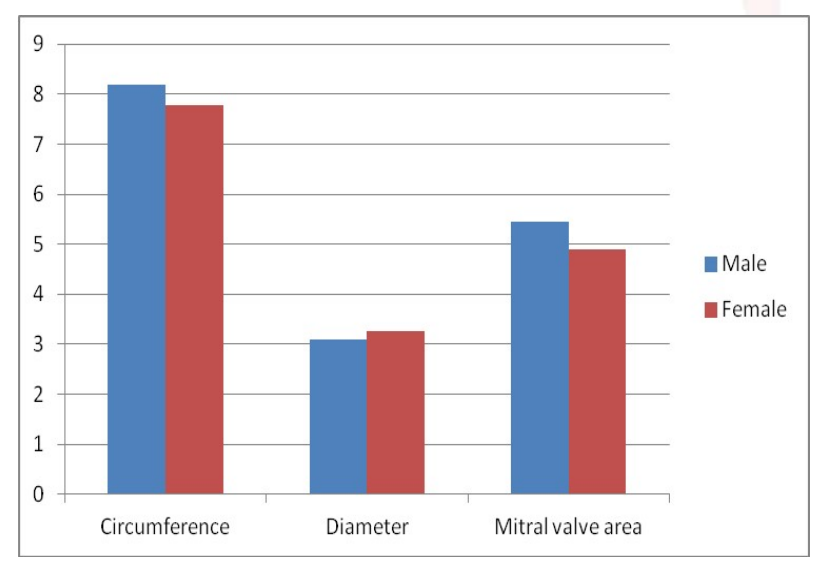

In the present study mean value of mitral valve were, diameter was $3.10 \pm 0.40 \mathrm{~cm}$ in males \& $3.26 \pm 0.48 \mathrm{~cm}$ in females, circumference of mitral valve was $8.19 \pm 1.01 \mathrm{~cm}$ in males \& $7.76 \pm 0.99 \mathrm{cms}$ in females, area of mitral valve was $5.45 \pm 1.34 \mathrm{~cm}^{2}$ in males \& $4.89 \pm 1.20 \mathrm{~cm}^{2} \mathrm{in}$ females.

All the parameters of mitral valve annulus like circumference, diameter $\&$ area of valve was more in males except in females the diameter were more. Correlation coefficient \& test of significant was applied showed no significent between male $\&$ female values ( $p>0.05$ ) 


\section{DISCUSSION}

\section{Mitral valve circumference:}

Table 2: Shows comparison of mitral valve circumference with other authors.

\begin{tabular}{|c|l|c|c|}
\hline S.No. & \multicolumn{1}{|c|}{ Authors } & $\begin{array}{c}\text { No. of cadaver } \\
\text { heart }\end{array}$ & $\begin{array}{c}\text { Annular } \\
\text { circumference }\end{array}$ \\
\hline 1 & Brock RC et al [8] & -- & $10.5(9.9)$ \\
\hline 2 & Rusted IE et al [9] & 50 & 9.9 \\
\hline 3 & Cheichi et al [10] & -- & $10(\mathrm{M}), 9(\mathrm{~F})$ \\
\hline 4 & Duplessis LA et al [2] & 10 & 10.2 \\
\hline 5 & Mc alpine et al [11] & -- & 13.4 \\
\hline 6 & Silvermen et al [12] & $8-\mathrm{Dec}$ & 8 -Dec \\
\hline 7 & Ranganathan N et al [13] & 50 & $9(\mathrm{M}), 7.2(\mathrm{~F})$ \\
\hline 8 & Bulkly BH\& RobertsWC et al [14] & 24 & 9 \\
\hline 9 & Carpentier et al [15] & -- & $1.16 \pm 0.35$ \\
\hline 10 & Omriston JA et al [16] & $2 \mathrm{D}$ echo & $9.3 \pm 0.9$ \\
\hline 11 & Datta Ak et al [17] & 30 & $10.3(\mathrm{M}), 9.7(\mathrm{~F})$ \\
\hline 12 & Wesyby S et al [18] & 160 & $9.79 \pm 1.23$ \\
\hline 13 & Gerdal L et al [19] & -- & $10(\mathrm{M}), 9(\mathrm{~F})$ \\
\hline 14 & Kouji chida et al [20] & -- & $8.3 \pm 1.0$ \\
\hline 15 & Shahim et al [3] & -- & $10.7(\mathrm{M}), 9.16(\mathrm{~F})$ \\
\hline 16 & Sakai T et al [21] & 57 & $9.33 \pm 1.1$ \\
\hline 17 & Andrade NMM et al [22] & -- & 7.92 \\
\hline 18 & Henry gray et al [1] & -- & $9(\mathrm{~m}), 7.2(\mathrm{~F})$ \\
\hline 19 & Patil D et al [23] & 50 & 8.24 \\
\hline 20 & Gupta C et al [24] & 18 & $9.12 \pm 0.44$ \\
\hline 21 & Senthil kumar et al [25] & 45 & $7.92 \pm 0.14$ \\
\hline 22 & Kapil amgain et al [26] & 50 & $8.03 \pm 0.82$ \\
\hline 23 & Deopujar R et al [27] & -- & 8.27 \\
\hline 24 & Kibria GM et al [28] & 50 & $8.03 \pm 0.82$ \\
\hline 25 & Mishra PP et al [29] & 120 & $7.5 \pm 10$ \\
\hline 26 & Ilankathir S et al [6] & 50 & 8.29 \\
\hline 27 & Charanya $\mathrm{N}$ et al [30] & 60 & $8.86 \pm 0.16$ \\
\hline 28 & Gunnal SA et al [31] & 116 & $9.12 \pm 1.36$ \\
\hline 29 & Sriambika K et al [32] & 50 & $8.8 \pm 1$ \\
\hline 30 & Present study & 50 & $8.19 \pm 1.01(\mathrm{M})$, \\
\hline
\end{tabular}

Table 3: Shows comparison of mitral valve diameter reported by other authors.

\begin{tabular}{|c|l|c|c|}
\hline S.No. & \multicolumn{1}{|c|}{ Authors } & $\begin{array}{c}\text { Cadaveric } \\
\text { hearts }\end{array}$ & $\begin{array}{c}\text { Annular diameter mitral } \\
\text { valve in cms }\end{array}$ \\
\hline 1 & Hamilton DJ et al [33] & 60 & $3.5 \mathrm{~cm}-3 \mathrm{~cm}$ \\
\hline 2 & Broke RC et al [8] & & 2.5 \\
\hline 3 & Rusted IE et al [9] & 50 & $\begin{array}{c}2.5 \mathrm{~cm}(\mathrm{M}) \\
2.1 \mathrm{~cm}(\mathrm{~F})\end{array}$ \\
\hline 4 & Westby S et al [18] & 160 & $\begin{array}{c}3.23 \pm 0.39 \mathrm{~cm}(\mathrm{M}) \\
2.90 \pm 0.27 \mathrm{~cm}(\mathrm{~F})\end{array}$ \\
\hline 5 & Sakai T et al [21] & 57 & 2.23 \\
\hline 6 & Krishniaha M et al [4] & $2 \mathrm{D}$ echo & $2.19(\mathrm{M}), 1.96(\mathrm{~F})$ \\
\hline 7 & Gunnal SA et al [31] & 116 & $2.22 \pm 0.50$ \\
\hline 8 & Kapil amgain et al [26] & 50 & $2.56 \pm 0.32$ \\
\hline 9 & Senthil kumar B et al [25] & 45 & $2.54 \pm 0.07$ \\
\hline 10 & Sriambika K et al [32] & 50 & $2.7 \pm 0.32$ \\
\hline 11 & Present study & 50 & $\begin{array}{c}3.10 \pm 0.40 \mathrm{~cm}(\mathrm{M}) \\
3.29 \pm 0.48(\mathrm{~F})\end{array}$ \\
\hline
\end{tabular}

The present study measurement of annular diameter was more than all the other studies but less compared to Hamilton DJ et al [33] \& in males of Westaby $S$ et al [18] studies. The circumference of mitral annulus was less compared to studies done by others both in males \& females, more compared to studies done by Andrade NM et al M [22], Sriambika et al [32], Kibria et al [28], Mishra PP et al [29] studies. The area of mitral valve was less compared to other studies but more compared to studies done by Senthil kumar B et al [25], Mishra PPet al [29], Kapil amgain et al [26], Carpentier A et al [15] studies.

The present study, when Compared to majority of other authors we found diameter of mitral annulus was more \& lesser values with circumference $\&$ area of the valve. But there was variation in the values of other parameters of mitral valve when compared to other studies. Our study mainly includes cadaveric hearts from Indian population which showed different dimensions on many above mentioned parameters when compared to the results of others study. This can be attributed to difference in age, sex, region of study, nature of specimen studied \& races of the population studied. Hence the knowledge of normal measurements of the component parts of the valve is essential for the surgeon during operation in this region assessing the exact mechanical reason for valve insufficiency \& in the development and manufacture of prosthesis for valvuloplasty.

Table 4: Shows comparison of mitral valve area reported by different authors.

\begin{tabular}{|c|l|c|c|}
\hline S.No. & \multicolumn{1}{|c|}{ Authors } & $\begin{array}{c}\text { Cadaveric } \\
\text { heart }\end{array}$ & Area of mitral valve \\
\hline 1 & Chiechi, MA et al [10] & 105 & $\begin{array}{c}7.93 \mathrm{~cm}^{2}(\mathrm{M}) \\
6.42 \mathrm{~cm}^{2}(\mathrm{~F})\end{array}$ \\
\hline $\mathbf{2}$ & Carpentier A et al [15] & -- & $3.2 \pm 1.3$ \\
\hline 3 & Westaby S et al [18] & 160 & $7.7 \pm 1.93 \mathrm{~cm}^{2}$ \\
\hline 4 & Bezzare AJC et al [34] & 91 & $9.049 \mathrm{~cm}^{2}$ \\
\hline $\mathbf{5}$ & Gupta C et al [24] & 18 & $7.3(\mathrm{M}), 6.2(\mathrm{~F})$ \\
\hline $\mathbf{6}$ & Senthil kumar B et al [25] & 45 & $5.04 \pm 0.01$ \\
\hline 7 & Kapil amgain et al [26] & 50 & $2.56 \pm 0.32$ \\
\hline $\mathbf{8}$ & Kibria GM et al [28] & 37 & $6.89 \pm 1.24$ \\
\hline 9 & Mishra PP et al [29] & 120 & $5.1 \pm 7.5$ \\
\hline 10 & Sriambika K et al [32] & 50 & $6.2 \pm 1.46$ \\
\hline 11 & Present study & 50 & $5.45 \pm 1.34 \mathrm{~cm}^{2}(\mathrm{M})$, \\
\hline
\end{tabular}

\section{CONCLUSION}

The disorders involving the valves of the heart disturbs the pumping efficiency of the heart. They produce either stenosis or regurgitation. Detailed knowledge of the anatomical characteristics of the mitral valve should improve the understanding of its anatomy and help much to 
obtain the better results in conservative procedures and in this way promoting return to anatomical and functional normality. This precise knowledge also defines some details of the architecture of the mitral valve that are necessary for the development and manufacture of the prosthesis. This will be helpful for both anatomist \& cardiac surgeons, in surgical procedures such as mitral valvuloplasty \& prosthetic valve replacement.

\section{Conflicts of Interests: None}

\section{REFERENCES}

[1]. Susan Standring, Neil R Borley, Patricia Collins, Alan R Crossman, Michael A Gatzoulis, Jeremiah C Healy, et al. Gray's Anatomy, The Anatomical basis of clinical practice. 40th ed. Elseiver: Churchill Livingstone; 2008;970-972.

[2]. Louis A. Du Plessis and Paul Marchand. The Anatomy of the mitral valve and its associated structures. Thorax 1964;19:221-227.

[3]. Shamim Akthar Cheema, Anjum Jalal, Nazeem Feroze, Jawad Sajid Khan. Dimensions of Mitral Valve of Normal Human Hearts in Pakistani Subjects. Pakistan Heart Journal 1996;29:32-36.

[4]. Krishnaiah M, Mrudula C. Morphometric Study of Mitral Valve Orifice an Echocardiographic Study. International Journal Of Pharma and Biosciences 2011;2:181-187.

[5]. Tei C, Pilgrim JP, Shah PM, Ormiston JA, Wong M. The tricuspid valve annulus: study of size and motion in normal subjects and in patients with tricuspid regurgitation. Circulation 1982;66:665-71.

[6]. Ilankathir S. A Cadaveric Study on Adult Human Heart Valve Annular Circumference and Its Clinical Significance. IOSR Journal of Dental and Medical Sciences 2015;14:60-64.

[7]. Howard S Richter. Mitral valve Area: Measurement soon Catheterization: Report of a Case. Circulatuion 1963;28:451-454.

[8]. Brock RC. The surgical and pathological anatomy of the mitral valve. Br Heart J 1952;14:489-513.

[9]. Rusted IE, Schiefley CH, Edwards JH, Studies of the mitral valve 1 . Anatomic features of the normal mitral valve and associated structures. Circulation 1952;6:825-31.

[10]. Chiechi MA, Lee WM and Thompson R. Functional anatomy of the normal mitral valve. Journal of thoracic surgery. 1956;32(3):378-98.

[11]. Mc Alpine WA. The Mitral Valve, In: Heart and Coronary Arteries. Springer, New York 1975;52-56.

[12]. Silvermen ME, Hurts JW. The mitral complex, interaction of anatomy, physiology, and pathology of the mitral annulus, mitral valve leaflets, chordae tendinae, and papillary muscles. American heart Journal 1968;76(3):399-418.
[13]. Ranganathan N, Lam JHC, Wigle E.D. Morphology of the human mitral valve II. The valve leaflets circulation 1970;41:459-67.

[14]. Bulkley BH, Roberts W.C. Dilatation of the mitral annulus: a rare cause of mitral regurgitation. Am J Med 1975;59:457-63.

[15]. Carpentier A, Guerinon J, Deloche A, Fabiani JN, Relland J. Pathology of the mitral valve. In: Kalmanson D editors. The mitral valve. London: Edward Arnold1976;65-77.

[16]. Ormiston J.A., Shah P.M. Tei C, and Wong M et al. Size and motion of the mitral valve annulus in man: 1 . A bio-dimensional echocardiographic method and findings in normal subjects. Circulation 1981;64:113.

[17]. Datta AK, Mukherjee MM, Ghosh S. Morphology and Morphometry of the mitral valve in normal human heart. Indian Heart Journal 1984;36:6.

[18]. Westaby S, Karp RB, Blackstone EH, Bishop SP. Adult human valve dimensions and their surgical significance. Am J Cardiol. 1984;53(4):552-6.

[19]. Gerda L. Van Rijk - Zwikker MD, Ben J. Delemarre, M.D., and Hars A. Huysmans M.D. Mitral valve anatomy \& Morphology:Relevance to mitral valve replacement \& valve reconstruction. J Card Surg 1994;9:255-261.

[20]. Kouji Chida, Shin-ichiro ohkawa, chizuko watanabe, hiroyuki shimada, kohichiro ohtsubo, Masaya sugiura. A morphological study of normally ageing heart. Cardiovasc Pathol 1994;3(1):1-7.

[21]. Sakai T, Okita $Y$, Ueda $Y$, Tahata T, Ogino $H$, Matsuyama K, Miki S. Distance between mitral anulus and papillary muscles: anatomic study in normal human hearts. The Journal of thoracic and cardiovascular surgery 1999;118(4):636-41.

[22]. Andrade NMM, Tinois E, Vieira, RW, Braile DM, Petrucci Junior O, Oliveira PPMD, Silveira Filho LD. Coefficient of proportions of the atrioventricular valves- An anatomical study of valvular segments of normal individuals. Brazilian Journal of Cardiovascular Surgery 2005;20(3):255-260.

[23]. Patil D, Mehta C, Prajapati P. Morphology of Mitral valve in Human cadavers. Internet Journal of Cardiology 2009;7:2.

[24]. Gupta C, Shetti VR, Manju BVM. Dimensions of the human adult mitral valve in the embalmed cadaver. J.Morphol.Sci 2013;30:6-10.

[25]. Senthil kumar B, Anand A. morphometric study of mitral valve in human hearts - a comparative anatomical study. int j pharm bio sci 2013;4(4):105110

[26]. Kapil Amgain, Sujit Kumar Thakur, Rajendrakumar Dundappa Virupaxi, Daksha Dixit, Suresh Pitambarappa Desai, Mohan Gan. Mitral valve size measurement in North Karnataka by using cardiac sizer: A cadaveric study. Arch Med Health Sci 2013;1:105-8.

[27]. Deopujari R, Sinha U, Athavale S A. Anatomy of left atrioventricular valve (mitral valve) leaflets in adult Indian cadavers. Int. J. Morphol2013;31(4):12761281. 
[28]. Kibria GM. The Morphometric Measurements of the Gross Structural Changes of Mitral Valve in Valvular Stenosis With or Without Regurgitation. Faridpur Med. Coll. J. 2014;9(1):07-11

[29]. Mishra PP, Rao MP, Paranjape V, Kulkarni JP. Morphometry of Mitral valve. Medical Journal of Dr. D.Y. Patil University. 2014;7(5):625-630.

[30]. Charanya N, Rajathi G, Vishali N. Morphological And Morphometrical Analysis Of Mitral Valve Annulus Of Heart In Human Adult Cadavers International Journal of Anatomy and Research. Int J Anat Res 2017;5:4405-09.

[31]. unal SA, Farooqui MS, Wabale RN. Study of Mitral Valve in Human Cadaveric Hearts. Heart views 2012;13(4):132-135.
[32]. Sriambika K, Virender Kumar Nim, Nutan Nalini Bage. Morphological And Morphometric Study Of Mitral Valve With Reference To Anatomical Variability In South Indian Subjects. Int J Anat Res 2018;6(4.3):5994-97.

[33]. Hamilton DJ. Effect of Chronic Disease of the Valves of the Heart upon the Sound Orifices, the Cavities and the Walls. J Anat Physiol 1888;23(1):40-68.

[34]. Bezerra AJC, DiDiO LJA, Prates JC. Variations of the area and shape of the left atrioventricular valve and its cusps and leaflets. Surg Radiol Anat 1994;16:277-280.

How to cite this article:

Geethanjali. B.S, Jayanthi V, Kavimani, Varsha Mokhasi, Rajini. T, Mohan kumar. H. THE ANATOMICAL STUDY OF MITRAL VALVE ANNULUS IN THE HUMAN CADAVERIC HEARTS FOR BIOPROSTHESIS. Int J Anat Res 2019;7(2.2):6575-6580. DOI: 10.16965/ijar.2019.173 